\title{
Validation of the English version of the Mood Rhythm Instrument
}

\author{
Melissa A. B. Oliveira ${ }^{1,2 \dagger}$, Kristina Epifano ${ }^{3 \dagger}$, Salina Mathur ${ }^{3}$, Felipe Gutiérrez Carvalho ${ }^{1,4}$, Marina Scop', \\ Alicia Carissimi 1,2, Ana Paula Francisco ${ }^{1}$, Luciene L. S. Garay ${ }^{1}$, Ana Adan ${ }^{5,6}$, Maria Paz Hidalgo ${ }^{1,2}$ and \\ Benicio N. Frey ${ }^{4,7^{*}}$
}

\begin{abstract}
Background: Disruption of biological rhythms has been linked to the pathophysiology of mental disorders. However, little is known regarding the rhythmicity of mood symptoms due to the lack of validated clinical questionnaires. A better understanding of the rhythmicity of mood symptoms can help identifying individuals whose severity of mood symptoms follows an altered circadian rhythm. The objective of this study was to validate the English version of the Mood Rhythm Instrument (MRhl), a self-reported measure of self-perceived rhythmicity of mood symptoms and behaviours, in a sample of the general population from Canada.

Methods: After the translation process, the final English version of the Mood Rhythm Instrument (MRhl-English) was applied on participants recruited at McMaster University and St. Joseph's Healthcare Hamilton campuses. Individuals were also asked to answer the Reduced Morningness-Eveningness Questionnaire (rMEQ).

Results: Four hundred one individuals completed the English version of the MRhl and the rMEQ. The MRhI-English presented a Cronbach's alpha of 0.75. The factorial analysis grouped the MRhl-15 items in 3 factors (cognitive, affective and somatic), with affective items having a lower frequency of self-reported 24-h peaks. Comparison between sexes showed that women reported a higher frequency of daily peaks in irritability, anxiety, sadness and talking to friends, while men exhibited peaks more frequently in problem-solving, sexual arousal and motivation to exercise.

Conclusions: Our findings suggest that the English version of the MRhl displayed good internal consistency. Future directions will include the use of the MRhl instrument in individuals with mood disorders, aiming to provide a better understanding of the relationship between daily patterns of mood variability and mental health outcomes.
\end{abstract}

Keywords: Circadian rhythm, Chronobiology, Sleep, Depression, Mood

\section{Background}

Mood disorders are chronic mental health conditions that cause a range of disabilities for patients, generating a negative impact on the individual, health systems and society [1]. Due to their multifactorial etiology, mood

\footnotetext{
* Correspondence: freybn@mcmaster.ca

${ }^{+}$Melissa A. B. Oliveira and Kristina Epifano contributed equally as first authors ${ }^{4}$ Mood Disorders Program and Women's Health Concerns Clinic, St. Joseph's Healthcare, Hamilton, ON, Canada

${ }^{7}$ Department of Psychiatry and Behavioural Neurosciences, McMaster University, 100 West 5th Street, Suite C124, Hamilton, ON L8N 3K7, Canada Full list of author information is available at the end of the article
}

disorders are known to be influenced by genetic, personal and/or environmental factors [2, 3]. While mood disorders are prevalent, a significant proportion of individuals with mood disorders go undiagnosed due to the spectrum of severity and prognosis $[4,5]$. In this context, it is important to find ways to improve the identification of its risk factors, leading to appropriate treatment management and consequently preventing unfavourable outcomes.

The etiology of mood disorders has been extensively studied, and some chronobiological factors have been found to play an essential role in the pathophysiology of

(C) The Author(s). 2020 Open Access This article is licensed under a Creative Commons Attribution 4.0 International License, which permits use, sharing, adaptation, distribution and reproduction in any medium or format, as long as you give appropriate credit to the original author(s) and the source, provide a link to the Creative Commons licence, and indicate if changes were made. The images or other third party material in this article are included in the article's Creative Commons licence, unless indicated otherwise in a credit line to the material. If material is not included in the article's Creative Commons licence and your intended use is not permitted by statutory regulation or exceeds the permitted use, you will need to obtain permission directly from the copyright holder. To view a copy of this licence, visit http://creativecommons.org/licenses/by/4.0/ The Creative Commons Public Domain Dedication waiver (http://creativecommons.org/publicdomain/zero/1.0/) applies to the data made available in this article, unless otherwise stated in a credit line to the data. 
mood disorders [6]. For instance, previous studies have revealed that alterations in circadian rhythms are highly associated with major depression and bipolar disorder [7-9]. Specifically, altered variations of the clock genes, those involved with rhythmicity and timing of biological rhythms at a molecular level, have been found in individuals with bipolar disorder, as well as major depression [10]. Recent metaanalytic studies have concluded that the abnormal sleep rhythms are consistently observed in patients with these two major mood disorders $[11,12]$. These disturbances can be a potential predictor of declining mental health, as they have been shown to contribute to escalated mood levels and the triggering of manic episodes in patients [13]. For instance, studies have shown that sleep deprivation and jet lag can trigger or aggravate depressive, hypomanic or manic episodes [14]. In addition, studies have shown that discrete patterns of daily activity rhythms can distinguish specific mood disorder subgroups, such as bipolar depression and mania, or nonmelancholic and melancholic depression [15, 16]. Notably, lower stability and weakened amplitude in rest-activity rhythms have been associated with greater symptom severity (e.g. impulsivity and mood instability) in individuals with borderline personality disorder [17].

Therapies that target circadian rhythms synchronization might be useful in the management of mood disorders, such as bright light therapy and interpersonal and social rhythm therapy [18-20]. A better understanding of the rhythmicity of mood symptoms can help to identify individuals whose severity of mood symptoms follow an altered circadian rhythm. However, despite the increasing evidence linking mood disorders and circadian rhythms disruption, little is known regarding the rhythmicity of mood symptoms due to the lack of validated clinical questionnaires. In order to fill this gap, we have developed the Mood Rhythm Instrument (MRhI), a clinical tool aiming at assessing the self-perceived rhythmicity of mood symptoms.

The MRhI is a self-reported questionnaire developed to evaluate the presence and timing of daily patterns for mood-related symptoms over the last 15 days. Each of the 15 items comprises a categorical and a continuous question. The original version of this instrument was created in Brazilian Portuguese [21], which was then translated and validated in Spanish [22, 23]. In a large study with 708 participants that completed the MRhI, we found that the rhythmicity of specific mood-related symptoms and behaviors, such as pessimism and motivation to exercise were associated with higher risk for psychiatric disorders [24]. Notably, we also found specific cultural differences in comparing Spanish and Brazilian samples in terms of the daily patterns of moodrelated symptoms [25]. These results are consistent with previous studies suggesting that cultural differences, as seen in different populations' sleep/wake habits [26-28], as well as ethnic differences [29], and as racial differences in tau and circadian phase shifting, are relevant factors in circadian rhythm research. Thus, this study aims to validate the MRhI English version in an English-speaking Canadian sample.

\section{Methods}

\section{Step 1. Translation of the Mood Rhythm Instrument (MRhl)}

The translation process is detailed in Fig. 1 and was composed by five steps, including forward translation, correctness, back translation, back translation review and harmonization.

The instructions on how to answer the questionnaire was updated with the removal of one sentence. In the translated version, the following sentence was written: "Answer the following questions according to the previous 15 days, taking into account how you have felt during most of the time, on the majority of the days and in the absence of any events that have caused you distress". In order to improve clarity, this sentence was changed

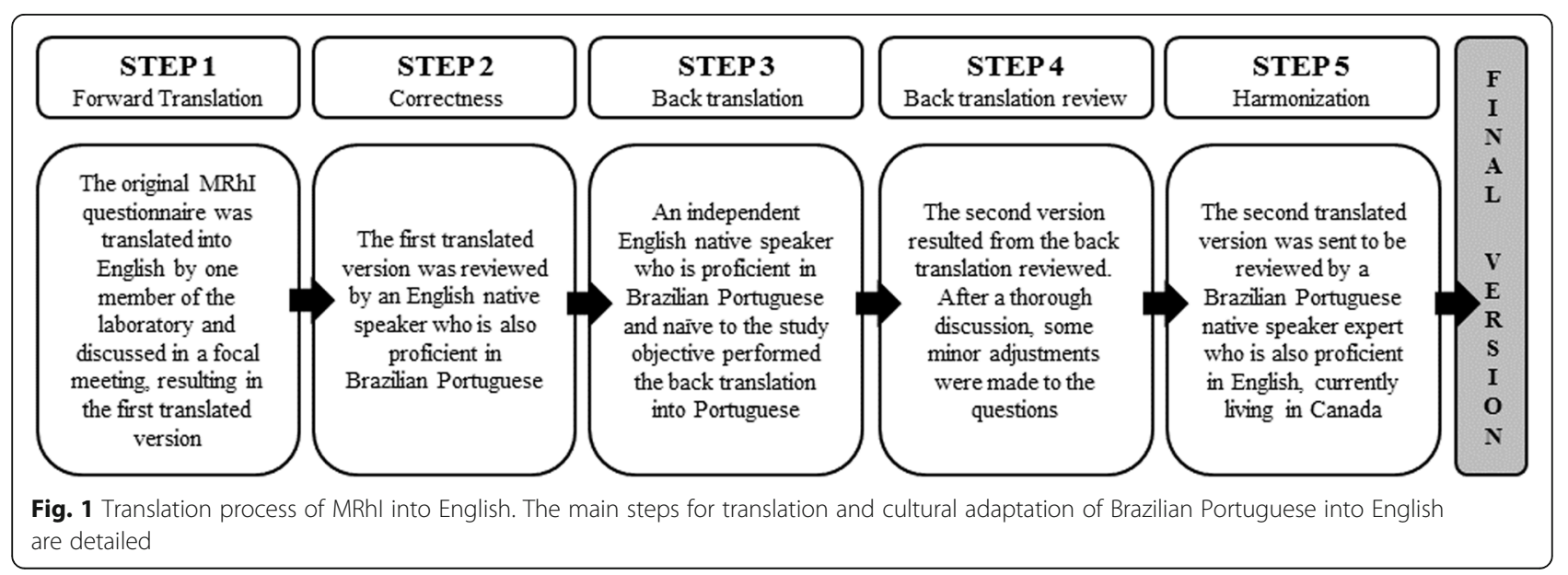


to: "Answer the following questions according to the previous 15 days, taking into account how you have felt during most of the time". All sentences had their conjugation changed to the Present Perfect Tense, as the $\mathrm{MRhI}$ intends to assess the self-perceived rhythmicity of mood-related symptoms in the last 15 days. For question 11, the word "prone" was changed to "motivated". For question 12, the sentence "you memorize" was changed to "your memory". For question 15, the sentence "when you feel your best" was changed to "when you have had more energy and motivation to do things". Furthermore, instead of a 24-h format scale as it stands in the Portuguese version, the English version has an am/pm format scale. The final English version of the MRhI can be found as Supplementary Methods.

\section{Step 2. Validation of the Mood Rhythm Instrument Participants and procedures}

Data collection was conducted between January 2016 and September 2018. We recruited the study sample through poster advertisements at McMaster University and St. Joseph's Healthcare Hamilton campuses, and online research recruitment within the Department of Psychology, Neuroscience \& Behaviour at McMaster University. The final study sample comprised 401 individuals (age: 18-60; mean age: $22 . \pm 7$ ), predominantly women (72\%), with a mean of $15 \pm 3$ years of schooling. The study was approved by the Hamilton Integrated Research Ethics Board and was conducted in accordance with the Declaration of Helsinki. All study participants provided written informed consent before study entry.

\section{Instruments}

Mood Rhythm Instrument (MRhI) The MRhI is composed of 15 items referring to physical, psychological and behavioural aspects related to mood, and each item provides a categorical (presence or absence of a daily peak) and a continuous (peak time in a $24 \mathrm{~h}$ period) variable. Subjects answered if, in the last 15 days, there was a specific time of the day when they experienced a peak in mood-related symptoms. We have recently completed a study where we tested the agreement rates between the MRhI and a daily version of the MRhI, and we found high agreement rates between the two instruments, thus suggesting that the MRhI may not be significantly influenced by memory bias [25]. The MRhI displayed a satisfactory internal consistency (i.e. Cronbach's alpha) in Brazilian (0.73) and Spanish (0.70) populations [21, 23].

Reduced Morningness-Eveningness questionnaire (rMEQ) The rMEQ provides a self-evaluation of chronotype, which is a unidimensional construct and offers a classification that varies between evening and morning types. This questionnaire was developed by Adan and Almirall [30] and includes items 1, 7, 10, 18, and 19 of the original MEQ. These 5 questions comprise the smallest possible number of items that provides the maximum amount of information relative to the time when each individual feel to be more prone to perform daily activities and to sleep. Higher numbers indicate morning tendencies and lower numbers indicate evening tendencies (scores 4-11: evening type; 12-17: intermediate type; 18-25: morning type). The rMEQ has been widely used due to its practicality, allowing parallel recording of other variables, especially in large sample studies. The psychometric properties of the rMEQ has been evaluated in many countries of Europe, America, as well as in Kingdom of Saudi Arabia, China, India, Iraq and Iran. In most of these previous studies rMEQ showed similar values for internal consistency [31].

\section{Reliability and validity process}

Internal consistency was measured with Cronbach's alpha. A Cronbach's alpha value between 0.7 and 0.9 was considered acceptable [32]. Psychometric properties of MRhI-English were assessed through the exploratory factor analysis (EFA). The EFA was carried out using a tetrachoric correlation matrix since our data has a binary feature [33]. Maximum Likelihood and Varimax were the extraction and rotation methods, respectively. Compared to other commonly used extraction methods, Maximum Likelihood uses the full information solution of the $2 \mathrm{p}$ contingency table [34]. For practical implications, Maximum Likelihood is considered preferable for tests with few factors (stated as 1 to 3 factors), which is the main reason we opted for this specific extraction method [35]. Satorra-Bentler corrected model estimation algorithm was used to surmount biased estimates. Varimax is a widely used rotation technique, being suitable for the present data as it shows excellent results by differentiating groups in several simulation scenarios [36]. Factors extraction was initially performed through Velicer's minimum average partial (MAP) [37], Horn's Parallel Analysis (PA) [38], and Comparison Data (CD) [39], obtaining 2, 5, and 3 factors respectively. As supported by Ruscio and Roche [39], CD method performs better than MAP and PA in terms of accuracy and precision, with nearly unbiased results. Thus, the three-factor model was considered for the analysis. A confirmatory factor analysis (CFA) using Comparative Fit Index $(\mathrm{CFI})>0.95$, Tucker-Lewis Index $(\mathrm{TLI})>0.95$, Root mean square error of approximation (RMSEA) $<0.06$, and Standardized Root Mean Square Residual (SRMR) < 0.08 as model fit indices were conducted [40]. The CFA model fit indices showed suitable or slightly less than 
Table 1 Exploratory Factor Analysis of the English version of the Mood Rhythm Instrument items based on a three-factor solution

\begin{tabular}{llll}
\hline Items & Factor 1 & Factor 2 & Factor 3 \\
\hline 1. Alertness & 0.43 & 0.16 & $\mathbf{0 . 4 5}$ \\
2. Sleepiness & 0.26 & 0.2 & $\mathbf{0 . 7 2}$ \\
3. Problem-Solving & $\mathbf{0 . 7 6}$ & 0.09 & 0.28 \\
4. Self-esteem & 0.15 & $\mathbf{0 . 4 5}$ & 0.44 \\
5. Concentration & $\mathbf{0 . 6 4}$ & 0.1 & 0.31 \\
6. Appetite & 0.12 & 0.19 & $\mathbf{0 . 5 4}$ \\
7. Sexual Arousal & 0.11 & 0.26 & $\mathbf{0 . 4 5}$ \\
8. Irritability & 0.15 & 0.37 & $\mathbf{0 . 4 9}$ \\
9. Anxiety & 0.1 & $\mathbf{0 . 6 6}$ & 0.21 \\
10. Sadness & 0.1 & $\mathbf{0 . 8 5}$ & 0.01 \\
11. Motivation to Exercise & 0.2 & -0.12 & $\mathbf{0 . 4 5}$ \\
12. Memory & $\mathbf{0 . 7 2}$ & 0.24 & 0 \\
13. Pessimism & 0.18 & $\mathbf{0 . 6 3}$ & 0.14 \\
14. Talking to Friends & $\mathbf{0 . 3 2}$ & 0.31 & 0.17 \\
15. Energy & $\mathbf{0 . 5 9}$ & 0.11 & 0.46 \\
Eigenvalues & 2.38 & 2.26 & 2.32 \\
\% of variance & 0.16 & 0.15 & 0.15 \\
\hline
\end{tabular}

the good fit values $\left(\chi^{2}=178.8, \mathrm{df}=87, \mathrm{CFI}=0.875\right.$, TLI $=$ $0.850, \mathrm{RMSEA}=0.05, \mathrm{SRMR}=0.06)$.

\section{Statistical analysis}

Variables were tested for normality by the Shapiro-Wilk test. Comparisons of the frequency of the dichotomous MRhI-
English according to sex were analyzed by Chi-square test $\left(x^{2}\right)$. Linear-circular correlations between time peaks of $\mathrm{MRhI}$ items and MEQ scores were performed [41]. The distribution of MRhI-English items peaks were shown as a circular mean and compared between sexes according to Mardia-Watson-Wheeler test, considering that the data do not follow a normal distribution for circular data [42]. $\mathrm{R}$ version 3.4.1 (package "Directional v3.3") and NCSS 12.0.9 were used for circular analysis. R version 3.4.1 (packages "psych", "lavaan" and "RGenData") and PASW Statistics Version 18 (SPSS Inc., Chicago, IL) were used for statistical analyses. Statistical significance was accepted at $p<0.05$.

\section{Results}

Reliability and validity of the English version of the mood rhythm instrument

The MRhI-English presented a Cronbach's alpha of 0.75 in this sample, which suggests good internal consistency. Table 1 presents the three factors obtained with the factorial analysis of the categorical MRhI items. The first factor was predominantly composed by cognitive items such as problem-solving, concentration, memory, talking to friends and energy. Items related to affective aspects were in the second factor, e.g. self-esteem, anxiety, sadness and pessimism. Finally, the third factor grouped alertness, sleepiness, irritability and somatic items like appetite, sexual arousal, and motivation to exercise.

The frequency of self-reported rhythmicity for each MRhI item and the comparison between sexes is shown on Table 2. Items with the highest reported occurrence (> $70 \%)$ of a daily peak were alertness, sleepiness, concentration, appetite and energy. On the other hand, less than

Table 2 Frequency of self-reported rhythmicity of the Mood Rhythm Instrument (MRhl) items - English version

\begin{tabular}{|c|c|c|c|c|}
\hline MRhl items & $\begin{array}{l}\text { Total }(n=401) \\
\mathrm{n}(\%)\end{array}$ & $\begin{array}{l}\text { Men }(n=112) \\
\mathrm{n}(\%)\end{array}$ & $\begin{array}{l}\text { Women }(n=289) \\
\mathrm{n}(\%)\end{array}$ & $x^{2}, p$ value \\
\hline Alertness & $313(78)$ & $85(76)$ & $228(79)$ & $0.42, p=0.52$ \\
\hline Sleepiness & $375(94)$ & $109(97)$ & $266(92)$ & $3.71, p=0.05$ \\
\hline Problem-solving & $273(68)$ & $85(76)$ & $188(65)$ & $4.36, p<0.05^{*}$ \\
\hline Self-esteem & $144(36)$ & $40(36)$ & $104(36)$ & $0.00, p=0.96$ \\
\hline Concentration & $318(79)$ & $86(77)$ & $232(80)$ & $0.60, p=0.44$ \\
\hline Appetite & $292(73)$ & $82(73)$ & $210(73)$ & $0.01, p=0.91$ \\
\hline Sexual Arousal & $125(31)$ & $47(42)$ & $78(27)$ & $8.44, p<0.01^{* *}$ \\
\hline Irritability & $243(61)$ & $58(52)$ & $185(64)$ & $5.06, p<0.05^{*}$ \\
\hline Anxiety & $172(43)$ & $34(30)$ & $138(48)$ & $9.97, p<0.01^{* *}$ \\
\hline Sadness & 157 (39) & $30(27)$ & $127(44)$ & $9.98, p=0.01^{* *}$ \\
\hline Motivation to exercise & $248(62)$ & $79(70)$ & $169(58)$ & $4.97, p=0.05^{*}$ \\
\hline Memory & $127(32)$ & $37(33)$ & $90(31)$ & $0.13, p=0.72$ \\
\hline Pessimism & $122(30)$ & $30(27)$ & $92(32)$ & $0.97, p=0.32$ \\
\hline Talking to Friends & $205(51)$ & $43(38)$ & $162(56)$ & $10.08, p<0.01^{* *}$ \\
\hline Energy & $310(77)$ & $86(77)$ & $224(78)$ & $0.02, p=0.88$ \\
\hline
\end{tabular}

Chi-square test; ${ }^{*} p<0.05 ;{ }^{* *} p \leq 0.01$ 


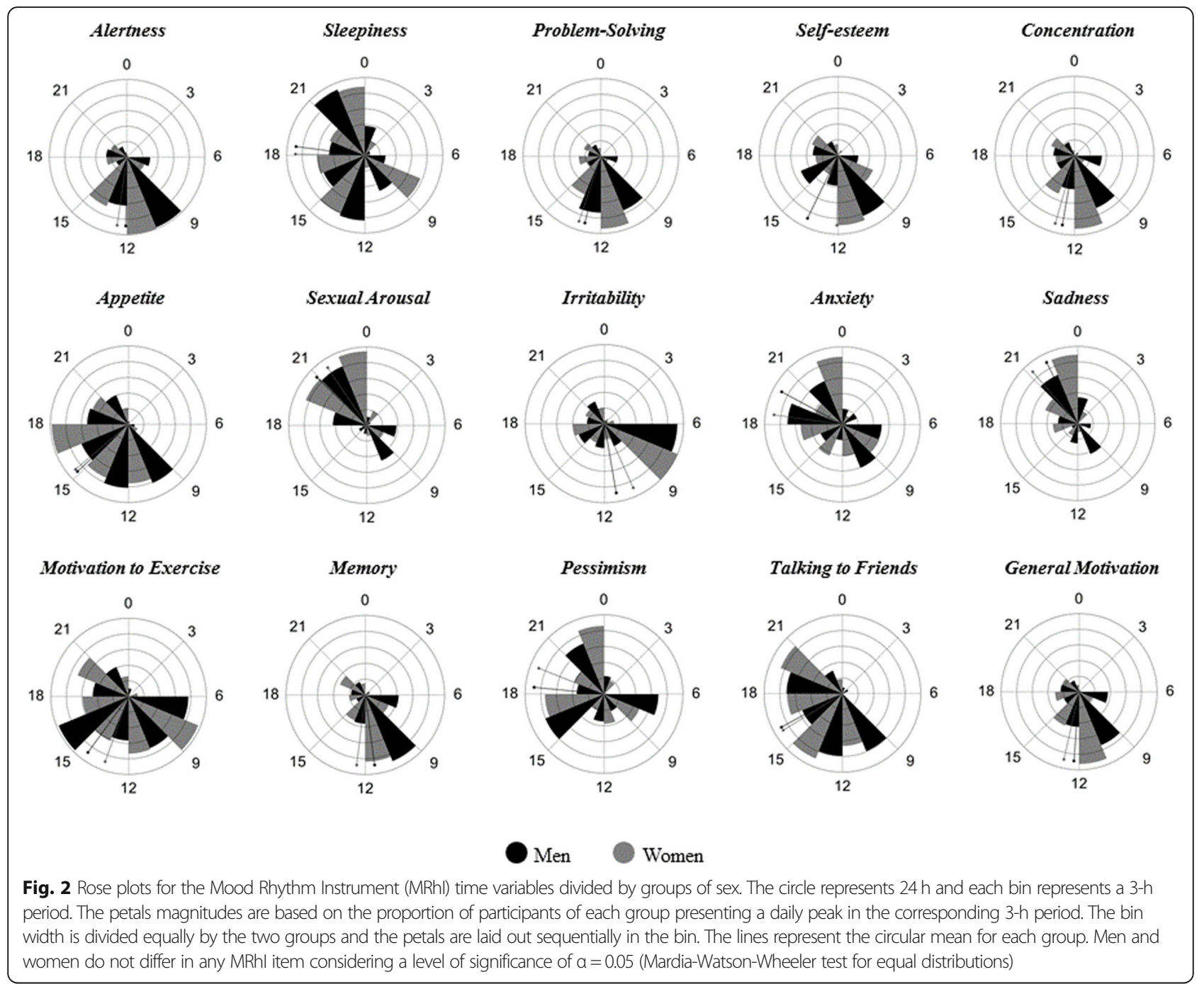

$40 \%$ of subjects reported a daily peak in self-esteem, sexual arousal, sadness, memory and pessimism. The comparison between sexes showed that women reported a higher frequency of daily patterns in irritability, anxiety, sadness and talking to friends, while men reported in problem-solving, sexual arousal and motivation to exercise.

The comparison of MRhI time variables distribution according to sex is displayed in Rose plots (Fig. 2). The items did not vary between men and women (all $p>$ 0.05). Notably, sleepiness, appetite, anxiety, motivation to exercise, pessimism and talking to friends seemed to have a multimodal (i.e. more than one peak time in a $24 \mathrm{~h}$ period) pattern of occurrence.

According to linear-circular correlation, all MRhI timing items were significantly correlated with rMEQ scores (Table 3). However, we cannot establish if items are positively or negatively correlated to rMEQ scores due to the nature of a circular measure. Figure 3 presents the frequency of which subjects responded with having a peak for
MRhI items and the circular means of the reported peaks according to chronotype. The later the circular means appeared for cognitive and somatic items, the more eveningness the chronotype became (e.g. alertness, problem-solving, concentration, appetite, motivation to exercise, memory, talking to friends and energy). The opposite occurred with irritability, sleepiness, anxiety and pessimism. Sexual arousal and sadness did not seem to vary among the different chronotypes and showed little rhythmicity.

\section{Discussion}

The translation of the MRhI to English was adjusted to language and clarity. Importantly, the time scale was modified into the 12-h clock format for a cultural adaptation for the Canadian and most English-speaking countries. The Cronbach's alpha was 0.75 , meaning that the items had an acceptable internal consistency and were adequate, similar to previous validation studies of the MRhI [21, 23]. 
Table 3 Linear-circular correlations between time of peak of MRhl items and rMEQ scores

\begin{tabular}{lll}
\hline MRhl items (n) & R-squared & $p$-value \\
\hline Alertness (309) & 0.290 & $\leq 0.001$ \\
Sleepiness (370) & 0.106 & $\leq 0.001$ \\
Problem-Solving (270) & 0.147 & $\leq 0.001$ \\
Self-esteem (142) & 0.206 & $\leq 0.001$ \\
Concentration (315) & 0.247 & $\leq 0.001$ \\
Appetite (289) & 0.028 & $\leq 0.001$ \\
Sexual Arousal (123) & 0.066 & $\leq 0.001$ \\
Irritability (241) & 0.203 & $\leq 0.001$ \\
Anxiety (170) & 0.089 & $\leq 0.001$ \\
Sadness (157) & 0.046 & $\leq 0.001$ \\
Motivation to Exercise (246) & 0.162 & $\leq 0.001$ \\
Memory (126) & 0.231 & $\leq 0.001$ \\
Pessimism (120) & 0.107 & $\leq 0.001$ \\
Talking to friends (203) & 0.020 & 0.018 \\
Energy (305) & 0.221 & $\leq 0.001$ \\
\hline Abbrevations: MEQ Reduced Mon
\end{tabular}

Abbreviations: $r M E Q$ Reduced Morningness-Eveningness Questionnaire

The three factors solution grouped the items based on the nature of their features. Considering that the first factor explains the greatest percentage of the variance, items in this factor are considered to have an important contribution to the explained variance [43]. It seems that in this Canadian sample, cognitive items are more important in assessing the profile of mood rhythmicity than affective and somatic ones. Yet, in the recent Spanish validation of MRhI, psychometric analysis showed that the first factor grouped somatic items except for problem-solving [23].

In line with previous MRhI studies, cognitive and somatic items had more reported peaks than affective items [21, 23]. With the exception of anxiety, the affective items exhibited perceived peaks on less than $40 \%$ of subjects from the whole sample. When considering sex to compare the frequency of daily peaks, we found significant differences in irritability, anxiety and sadness, which were more frequently reported by women. Notably, these results are consistent with epidemiological data pointing to a higher prevalence of mood and anxiety disorders in women, which is corroborated by biological [44] and socioeconomic [45] contributors. Another factor that may be related to the sex differences observed are alexithymic behaviors, which are more prevalent in men, resulting in a lack of report of negative emotions in this population [46].

Women also reported a higher frequency of daily peaks for talking to friends, which is in accordance to a previous British study that evaluated social interaction components of circadian rhythms through phone calls monitoring. Results showed that, comparatively to men, women spent more time on calls with friends in the evening and at night [47]. Interestingly, in terms of sexual arousal, men reported more frequency of sexual arousal peaks than women, which is exactly the opposite from what we observed in Spanish population [23] and also distinct from Brazilians that did not display differences in sexual arousal peak between women and men [21]. Moreover, problem-solving and motivation to exercise were more frequently pointed as having a daily peak in men. This result can be in part supported by the fact that women are more prone to be extrinsically motivated (with expectations to gain rewards or outcomes) to exercise than intrinsically motivated (aiming personal satisfaction and/or enjoyment), resulting in less motivation for regular physical activity in comparison to men [48]. In contrast to the Brazilian sample, where alertness was the only item that differed between sexes, with women reporting more frequently to have a peak than men [21], no differences with regards to alertness were found in the Canadian sample.

Overall, we observed that the Canadians reported more sex differences with regards to frequency of perceived peaks than the Brazilian sample. Regarding negative mood and somatic symptomatology, women reported more frequent peaks than men (irritability, anxiety and sadness), while for positive cognitive and somatic activity behaviors men reported more frequent peaks than women (sexual arousal, problem solving and motivation to exercise). As aforementioned, higher prevalence of mood symptoms in women possibly contrasts observations related to the affective items in a sample mostly composed by them. Thus, future research exploring these factors which controls for the relationship between sex and psychiatric symptoms shall bring valuable insights related to the sex differences observed.

The time when items peak did not differ between men and women in any of the MRhI items. Considering that participants could only choose one time peak, even though men reported to have a sexual arousal peak in the morning, pointed morning peaks were much more frequent as among women and, therefore, circular means were similar between women and men. A Polish study reported that women had evening peaks of "greatest need for sex", whereas men had both morning and evening peaks [49]. This multimodal pattern of occurrence was also identified in appetite and usually varies among breakfast, lunch and dinner [50]. Subjects also reported peaks of sleepiness in the morning, right after midday and at night which is in line with previous analyses of sleepiness expression [51].

As we expected, the circadian typology, measured by means of chronotype, is significantly correlated to all MRhI items time peaks [52]. Participants classified as morning types reported earlier peak times for concentration, alertness, problem-solving, energy, memory, motivation to exercise and self-esteem. In contrast, individuals classified as evening types reported that these items 

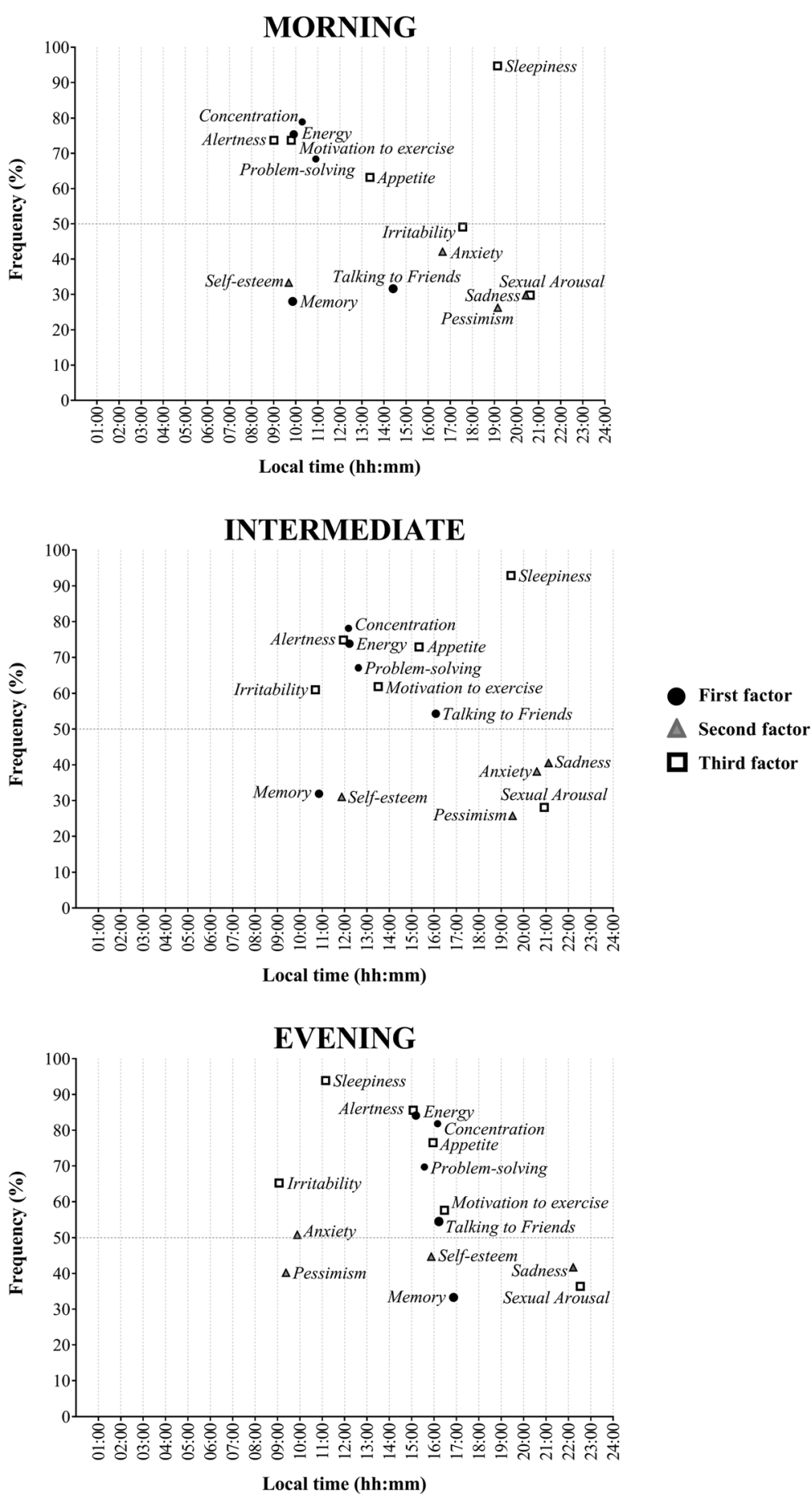

Fig. 3 Frequency and peak of each MRhl item. The circular mean of each 24-h peak for mood symptoms is depicted on the $x$-axis and frequency $(\%)$ is depicted on the $y$-axis

peaked later in the day. These results are consistent with previous studies from Europe and United States showing that individuals with morning chronotype performed better in terms of attention, alertness and working memory in the morning and afternoon when compared to individuals with an evening chronotype [53, 54]. Also, depending on the type of problem to solve (e.g. insight or analytic), individuals classified as having a later circadian arousal perform better during later afternoon sessions (between $4 \mathrm{pm}$ and 5:30 pm) [55].

Cognitive performance has been shown to be correlated with individual's body temperature rhythm. Wright et al. 
[56] found that cognitive tasks were performed better when body temperature is high and near its circadian peak. Alongside these findings, another study found that individuals with a morning chronotype have earlier temperature rhythms, thus their peaks in cognitive performance such as memory and alertness would also occur earlier than those with evening chronotypes [57]. Our data revealed that individuals with evening chronotype reported earlier peaks of sleepiness compared to individuals with morning and intermediate chronotypes. However, it is possible that this finding does not reflect spontaneous behaviors, but rather the consequences of sleep disruption related to diurnal social demands, a hypothesis that is endorsed by the same finding regarding irritability, pessimism and anxiety (earlier in evening chronotypes). Due to the mean age of $22.2 \pm 7$ years of our sample, which in general is related to later chronotypes [52], the opposite maladaptation for nocturnal activities could be observed in talking to friends. This item peaked at a similar time for intermediate and evening types, and earlier in morning types. Finally, in our sample sexual arousal, appetite and sadness displayed little variation between chronotypes.

This study has some limitations. We are aware that the MRhI does not reflect mood rhythms independently of external or social factors, as responsibilities and schedules of participants probably influence their responses. However, it is of our interest to evaluate individuals' self-perception of rhythmicity of mood-related symptoms when inserted in a real-life setting, rather than assessing internal rhythm alone. External factors that exist in a person's environment are intricate experiences that can also influence how symptoms of mood disorders present themselves. Another limitation is that only one external validation measure was used, albeit it is a well-established questionnaire to evaluate chronotype [30]. Longitudinal monitoring of cognitive, affective, and somatic symptoms using Ecological Momentary Assessment methods should also be considered when validating instruments like the MRhI.

\section{Conclusions}

In conclusion, the results obtained with the English version of the MRhI are consistent with previous chronobiology studies, suggesting that this instrument might be useful to enhance the knowledge of self-perceived daily patterns of mood-related symptoms. The Cronbach's alpha analysis suggests good internal consistency of this instrument. Cognitive, affective and somatic items presented different frequency of reported peaks and regarding its timing, they seemed to behave accordingly to chronotype. The future directions will be the use of the MRhI instrument in a large sample of individuals with mood disorders, aiming to provide a better understanding of the relationship between daily patterns of mood variability and mental disorders.

\section{Supplementary information}

Supplementary information accompanies this paper at https://doi.org/10. 1186/s40359-020-00397-2.

\section{Additional file 1.}

\section{Abbreviations}

MRhl: Mood Rhythm Instrument; rMEQ: Reduced Morningness-Eveningness Questionnaire; MRhl-English: English version of the Mood Rhythm Instrument; MAP: Minimum average partial; CD: Comparison Data; CFA: Confirmatory factor analysis; TLI: Tucker-Lewis Index; RMSEA: Root mean square error of approximation

\section{Authors' contributions}

M.A.B.O., A.C., A.P.F., A.A., M.P.H. and B.N.F. designed the study. M.A.B.O., K.E., M.S., S.M., F.G.C., A.C., A.P.F. and L.L.S.G. collected and organized the data. M.A.B.O, K.E., M.S., F.G.C., A.C. and M.P.H. analyzed the data. M.A.B.O., K.E., M.S., A.C., L.L.S.G., M.P.H and B.N.F. wrote the first draft of the manuscript. All authors have read, revised and approved the final manuscript.

\section{Funding}

Financial support was provided by CAPES (MO, FC), Propesq-UFRGS (MS), PQCNPq (MH), PVE-CNPq and PRINT-CAPES (BF), the Spanish Ministry of Economy, Industry, and Competitiveness (grant PSI2015-65026; MINECO / FEDER / UE) (AA). The funding bodies had no role in the study design, data collection, analysis, or interpretation, or in the writing of the manuscript.

\section{Availability of data and materials}

All data generated or analyzed during this study are included in this published article.

\section{Ethics approval and consent to participate}

All individuals who agreed to participate provided written informed consent. The study was approved by the Hamilton Integrated Research Ethics Board and was conducted in accordance with the Declaration of Helsinki.

\section{Consent for publication}

Not applicable.

\section{Competing interests}

The authors declare that they have no competing interests.

\section{Author details}

${ }^{1}$ Laboratório de Cronobiologia e Sono do Hospital de Clínicas de Porto Alegre (HCPA), Universidade Federal do Rio Grande do Sul (UFRGS), Porto Alegre, Rio Grande do Sul, Brazil. ²Programa de Pós-Graduação em Psiquiatria e Ciências do Comportamento - Faculdade de Medicina, UFRGS, Porto Alegre, Rio Grande do Sul, Brazil. ${ }^{3}$ Department of Psychology, Neuroscience \& Behaviour, McMaster University, Hamilton, ON, Canada. ${ }^{4}$ Mood Disorders Program and Women's Health Concerns Clinic, St. Joseph's Healthcare, Hamilton, ON, Canada. ${ }^{5}$ Department of Clinical Psychology and

Psychobiology, School of Psychology, University of Barcelona, Barcelona, Spain. ${ }^{6}$ Institute of Neurosciences, University of Barcelona, Barcelona, Spain. ${ }^{7}$ Department of Psychiatry and Behavioural Neurosciences, McMaster University, 100 West 5th Street, Suite C124, Hamilton, ON L8N 3K7, Canada.

Received: 27 June 2019 Accepted: 23 March 2020

Published online: 17 April 2020

References

1. Vos T, Barber RM, Bell B, Bertozzi-Villa A, Biryukov S, Bolliger I, et al. Global, regional, and national incidence, prevalence, and years lived with disability for 301 acute and chronic diseases and injuries in 188 countries, 1990-2013: A systematic analysis for the Global Burden of Disease Study 2013. Lancet 2015;386(9995):743-800 Available from: http://www.ncbi.nlm.nih.gov/ pubmed/26063472. [cited 2019 may 21].

2. Pittenger C, Duman RS. Stress, depression, and neuroplasticity: a convergence of mechanisms. Neuropsychopharmacology. 2008;33(1):88-109 Epub 2007 Sep 12. Review. PubMed PMID: 17851537. 
3. Krishnan V, Nestler EJ. Linking molecules to mood: new insight into the biology of depression. Am J Psychiatry. 2010;167(11):1305-20. https://doi. org/10.1176/appi.ajp.2009.10030434 Epub 2010 Sep 15. Review. PubMed PMID: 20843874; PubMed Central PMCID: PMC3031089.

4. Angst J, Azorin JM, Bowden CL, Perugi G, Vieta E, Gamma A, Young AH, BRIDGE Study Group. Prevalence and characteristics of undiagnosed bipolar disorders in patients with a major depressive episode: the BRIDGE study. Arch Gen Psychiatry. 2011;68(8):791-8. https://doi.org/10.1001/ archgenpsychiatry.2011.87 PubMed PMID: 21810644.

5. Shefer G, Henderson C, Howard LM, Murray J, Thornicroft G. Diagnostic overshadowing and other challenges involved in the diagnostic process of patients with mental illness who present in emergency departments with physical symptoms--a qualitative study. PLoS One. 2014;9(11):e111682. https://doi.org/10.1371/journal.pone.0111682 eCollection 2014. PubMed PMID: 25369130; PubMed Central PMCID: PMC4219761.

6. McClung CA. How might circadian rhythms control mood? Let me count the ways. Biol Psychiatry. 2013;74(4):242-9. https://doi.org/10.1016/j. biopsych.2013.02.019 Epub 2013 Apr 1. Review. PubMed PMID: 23558300; PubMed Central PMCID: PMC3725187.

7. Slyepchenko A, Allega OR, Leng X, Minuzzi L, Eltayebani MM, Skelly M, Sassi RB, Soares CN, Kennedy SH, Frey BN. Association of functioning and quality of life with objective and subjective measures of sleep and biological rhythms in major depressive and bipolar disorder. Aust N Z J Psychiatry. 2019;53(7):683-96. https://doi.org/10.1177/0004867419829228 Epub 2019 Feb 13. PubMed PMID: 30759998

8. Ávila Moraes C, Cambras T, Diez-Noguera A, Schimitt R, Dantas G, Levandovski R, Hidalgo MP. A new chronobiological approach to discriminate between acute and chronic depression using peripheral temperature, rest-activity, and light exposure parameters. BMC Psychiatry. 2013;13:77. https://doi.org/10.1186/1471-244X-13-77 PubMed PMID: 23510455; PubMed Central PMCID: PMC3599978.

9. Walker WH, Walton JC, DeVries AC, et al. Circadian rhythm disruption and mental health. Transl Psychiatry. 2020;10:28. https://doi.org/10.1038/s41398-020-0694-0.

10. Charrier A, Olliac B, Roubertoux P, Tordjman S. Clock genes and altered sleep-wake rhythms: Their role in the development of psychiatric disorders. Int J Mol Sci. 2017;18(5):938 Available from: http://www.ncbi.nlm.nih.gov/ pubmed/28468274. [cited 2019 May 21]

11. Geoffroy PA, Micoulaud Franchi JA, Lopez R, Poirot I, Brion A, Royant-Parola S, et al. Comment caractériser et traiter les plaintes de sommeil dans les troubles bipolaires ? Encephale. 2017;43(4):363-73 Available from: https://inkinghub. elsevier.com/retrieve/pii/S0013700616301804. [cited 2019 May 21].

12. Hertenstein E, Feige B, Gmeiner T, Kienzler C, Spiegelhalder K, Johann A, et al. Insomnia as a predictor of mental disorders: A systematic review and metaanalysis. Sleep Med Rev. 2019;43:96-105 Available from: https:/linkinghub. elsevier.com/retrieve/pii/S1087079218301138. [cited 2019 May 21].

13. Boivin DB. Influence of sleep-wake and circadian rhythm disturbances in psychiatric disorders. J Psychiatry Neurosci. 2000;25(5):446-58 Available from: http://www.ncbi.nlm.nih.gov/pubmed/11109296. [cited 2019 may 21].

14. Proudfoot J, Whitton A, Parker G, Doran J, Manicavasagar V, Delmas K. Triggers of mania and depression in young adults with bipolar disorder. J Affect Disord. 2012;143(1-3):196-202 Available from: http://www.ncbi.nlm. nih.gov/pubmed/22884233. [cited 2019 may 21].

15. Tonon AC, Fuchs DFP, Barbosa Gomes W, Levandovski R, Pio de Almeida Fleck $M, M P L H$, et al. Nocturnal motor activity and light exposure: Objective actigraphy-based marks of melancholic and non-melancholic depressive disorder. Brief report. Psychiatry Res. 2017;258:587-90 Available from: https:// linkinghub.elsevier.com/retrieve/pii/S016517811730608X. [cited 2019 May 21]

16. Krane-Gartiser K, Vaaler AE, Fasmer OB, Sørensen K, Morken G, Scott J. Variability of activity patterns across mood disorders and time of day. BMC Psychiatry. 2017;17(1):404.

17. McGowan NM, Goodwin GM, Bilderbeck AC, Saunders KEA. Actigraphic patterns, impulsivity and mood instability in bipolar disorder, borderline personality disorder and healthy controls. Acta Psychiatr Scand. 2020. https:// doi.org/10.1111/acps.13148 [Epub ahead of print] PubMed PMID: 31916240.

18. Bottai T, Biloa-Tang M, Christophe S, Dupuy C, Jacquesy L, Kochman F, et al. Thérapie interpersonnelle et aménagement des rythmes sociaux (TIPARS) : du concept anglo-saxon l'expérience franaise. Encephale. 2010;36(SUPPL. 6): S206-17 Available from: http://www.ncbi.n/m.nih.gov/pubmed/21237358. [cited 2019 May 21].
19. Haynes PL, Gengler D, Kelly M. Social Rhythm Therapies for Mood Disorders: an Update. Curr Psychiatry Rep. 2016;18(8):75 Available from: http://link. springer.com/10.1007/s11920-016-0712-3. [cited 2019 May 21].

20. Pail G, Huf W, Pjrek E, Winkler D, Willeit M, Praschak-Rieder N, et al. Brightlight therapy in the treatment of mood disorders. Neuropsychobiology. 2011;64(3):152-62 Available from: http://www.ncbi.nlm.nih.gov/pubmed/21 811085. [cited 2019 may 21].

21. De Souza CM, Carissimi A, Costa D, Francisco AP, Medeiros MS, Ilgenfritz CA, et al. The mood rhythm instrument: Development and preliminary report. Rev Bras Psiquiatr. 2016;38(2):148-53 Available from: http://www.scielo.br/ scielo.php?script=sci_arttext\&pid=S1516-44462016000200148\&lng=en\&tlng= en. [cited 2019 May 21].

22. Francisco AP, de Oliveira MAB, Carissimi A, Fabris RC, Ilgenfritz CAV, de Souza CM, et al. Spanish Translation of the Mood Rhythm Instrument: a Novel Approach To Mood Evaluation. Clin Biomed Res. 2017;37(1):41-7 Available from: doi: 10.4322/2357-9730.69877. [cited 2019 May 21].

23. Carissimi A, Oliveira MAB, Frey BN, Navarro JF, Hidalgo MP, Adan A. Validation and psychometric properties of the Spanish mood rhythm instrument. Biol Rhythm Res. 2019. https://doi.org/10.1080/09291016.2019.1675023.

24. Pilz LK, Carissimi A, Oliveira MAB, Francisco AP, Fabris RC, Medeiros MS, et al Rhythmicity of Mood Symptoms in Individuals at Risk for Psychiatric Disorders. Sci Rep. 2018;8(1):11402 Available from: http://www.ncbi.nlm.nih. gov/pubmed/30061722. [cited 2019 May 21].

25. Pilz LK, Carissimi A, Francisco AP, Oliveira MAB, Slyepchenko A, Epifano K, et al. Prospective assessment of daily patterns of mood-related symptoms. Front Psychiatry. 2018;9 (AUG). Available from: https://www.frontiersin.org/ article/10.3389/fpsyt.2018.00370/full. [cited 2019 May 21].

26. Mistlberger RE, Skene DJ. Social influences on mammalian circadian rhythms: animal and human studies. Biol Rev Camb Philos Soc. 2004;79(3): 533-56 Available from: http://www.ncbi.nlm.nih.gov/pubmed/15366762. [cited 2019 may 21]

27. Gradisar M, Gardner G, Dohnt H. Recent worldwide sleep patterns and problems during adolescence: A review and meta-analysis of age, region, and sleep. Sleep Med. 2011;12(2):110-8 Available from: https://linkinghub. elsevier.com/retrieve/pii/S1389945710004326. [cited 2019 May 21].

28. Soldatos CR, Allaert FA, Ohta T, Dikeos DG. How do individuals sleep around the world? Results from a single-day survey in ten countries. Sleep Med. 2005;6(1):5-13 Available from: https://linkinghub.elsevier.com/retrieve/pii/ S1389945704001935. [cited 2019 May 21].

29. Smith MR, Burgess HJ, Fogg LF, Eastman Cl. Racial differences in the human endogenous circadian period. Yamazaki S, editor. PLoS One. 2009;4(6):e6014 Available from: https:/dx.plos.org/10.1371/journal.pone.0006014. [cited 2019 May 21].

30. Adan A, Almirall H. Horne \& Östberg morningness-eveningness questionnaire: A reduced scale. Pers Individ Dif. 1991;12(3):241-53 Available from: https://www.sciencedirect.com/science/article/pii/019188699190110W. [cited 2019 May 21]

31. Danielsson K, Sakarya A, Jansson-Fröjmark M. The reduced MorningnessEveningness questionnaire: psychometric properties and related factors in a young Swedish population. Chronobiol Int. 2019;36(4):530-40. https://doi.org/ 10.1080/07420528.2018.1564322 Epub 2019 Jan 7. PubMed PMID: 30614272.

32. Tavakol M, Dennick R. Making sense of Cronbach's alpha. Int J Med Educ. 2011;2:53-5 Available from: http://www.ncbi.nlm.nih.gov/pubmed/2802 9643. [cited 2019 May 21].

33. Bartholomew DJ, Steele F, Moustaki I, Galbraith J. Analysis of Multivariate Social Science Data, Second Edition. Int Stat Rev. 2008;76(3):456 Available from: http:// doi.wiley.com/10.1111/j.1751-5823.2008.00062_21.x. [cited 2019 May 21].

34. Mislevy R. Recent developments in the factor analysis of categorical variables. J Educ Stat. 1986;11(1):3-31. https://doi.org/10.2307/1164846.

35. Bock RD, Gibbons R, Muraki E. Full-information item factor analysis. Appl Psychol Meas. 1988;12(3):261-80. https://doi.org/10.1177/ 014662168801200305

36. Finch WH. A Comparison of Factor Rotation Methods for Dichotomous Data. J Mod Appl Stat Methods. 2011;10(2):Article 14. https://doi.org/10. 22237/jmasm/1320120780.

37. Velicer WF. Determining the number of components from the matrix of partial correlations. Psychometrika. 1976;41(3):321-7 Available from: http:// link.springer.com/10.1007/BF02293557. [cited 2019 May 21].

38. Horn JL. A rationale and test for the number of factors in factor analysis. Psychometrika. 1965;30(2):179-85 Available from: http://link.springer.com/1 0.1007/BF02289447. [cited 2019 May 21]. 
39. Ruscio J, Roche B. Determining the number of factors to retain in an exploratory factor analysis using comparison data of known factorial structure. Psychol Assess. 2012;24(2):282-92 Available from: http://www.ncbi. nlm.nih.gov/pubmed/21966933. [cited 2019 May 21].

40. Brown TA. Methodology in the social sciences. Confirmatory factor analysis for applied research. 2nd ed. New York: The Guilford press; 2015.

41. Mardia KV, Jupp PE. Directional Statistics. Hoboken: Wiley; 1999. (Wiley Series in Probability and Statistics). Available from: http://doi.wiley.com/10.1002/ 9780470316979. [cited 2019 May 21].

42. Mardia KV. Statistics of directional data. J R Stat Soc Ser B Methodol. 1975; 37:349-93.

43. Nias DKB. The handbook of psychological testing. Vol. 20, personality and individual differences. Florence: Taylor \& Frances/Routledge; 2003. p. 128.

44. Kuehner C. Why is depression more common among women than among men? Lancet Psychiatry. 2017:4(2):146-58.

45. Lim GY, Tam WW, Lu Y, Ho CS, Zhang MW, Ho RC. Prevalence of Depression in the Community from 30 Countries between 1994 and 2014/692/699/ 476/1414 /692/499 article. Sci Rep. 2018;8(1):2861 Available from: http:// www.nature.com/articles/s41598-018-21243-x. [cited 2019 May 21].

46. Sullivan L, Camic PM, JSL B. Masculinity, alexithymia, and fear of intimacy as predictors of UK men's attitudes towards seeking professional psychological help. Br J Health Psychol. 2015;20(1):194-211 Available from: http://doi.wiley. com/10.1111/bjhp.12089. [cited 2019 May 21].

47. Aledavood T, López E, Roberts SGB, Reed-Tsochas F, Moro E, Dunbar RIM, et al. Daily rhythms in mobile telephone communication. Lambiotte $R$, editor. PLoS One. 2015;10(9):e0138098 Available from: https://dx.plos.org/1 0.1371/journal.pone.0138098. [cited 2019 May 21].

48. Ryan RM. Intrinsic motivation and exercise adherence. Int I Sport Psychol. 1997;28(4):335-54 Available from: https://www.researchgate.net/ publication/279910235_Intrinsic_Motivation_and_Exercise_Adherence.

49. Jankowski KS, Díaz-Morales JF, Randler C. Chronotype, gender, and time for sex. Chronobiol Int. 2014;31(8):911-6 Available from: http://www.ncbi.nlm. nih.gov/pubmed/24927370. [cited 2019 May 21].

50. Scheer FAJL, Morris CJ, Shea SA. The internal circadian clock increases hunger and appetite in the evening independent of food intake and other behaviors. Obesity. 2013;21 (3):421-3 Available from: http://doi.wiley.com/1 0.1002/oby.20351. [cited 2019 May 21].

51. Campbell SS, Murphy PJ. The nature of spontaneous sleep across adulthood. J Sleep Res. 2007;16(1):24-32 Available from: http://doi.wiley. com/10.1111/j.1365-2869.2007.00567.x. [cited 2019 May 21].

52. Adan A, Archer SN, Hidalgo MP, Di Milia L, Natale V, Randler C. Circadian typology: A comprehensive review. Chronobiol Int. 2012;29(9):1153-75 Available from: http://www.tandfonline.com/doi/full/10.3109/07420528.2012. 719971. [cited 2019 May 21].

53. Matchock RL, Toby Mordkoff J. Chronotype and time-of-day influences on the alerting, orienting, and executive components of attention. Exp Brain Res. 2009;192(2):189-98 Available from: http://ink.springer.com/10.1007/ s00221-008-1567-6. [cited 2019 May 21].

54. Schmidt C, Collette F, Reichert CF, Maire M, Vandewalle G, Peigneux P, et al. Pushing the limits: Chronotype and time of day modulate working memory-dependent cerebral activity. Front Neurol. 2015;6(SEP):199 Available from: http://journal.frontiersin.org/Article/10.3389/fneur.2015.00199/abstract. [cited 2019 May 21].

55. Wieth MB, Zacks RT. Time of day effects on problem solving: when the nonoptimal is optimal. Think Reason. 2011;17(4):387-401.

56. Wright KP, Hull JT, Czeisler CA. Relationship between alertness, performance, and body temperature in humans. Am J Physiol Integr Comp Physiol. 2015; 283(6):R1370-7 Available from: http://www.physiology.org/doi/10.1152/ ajpregu.00205.2002. [cited 2019 May 21].

57. Lack L, Bailey M, Lovato N, Wright H. Chronotype differences in circadian rhythms of temperature, melatonin, and sleepiness as measured in a modified constant routine protocol. Nat Sci Sleep. 2009;1:1-8 Available from: http:// www.ncbi.nlm.nih.gov/pubmed/23616692\%0A. http://www.pubmedcentral. nih.gov/articlerender.fcgi?artid=PMC3630920. [cited 2019 May 21].

\section{Publisher's Note}

Springer Nature remains neutral with regard to jurisdictional claims in published maps and institutional affiliations.

\section{Ready to submit your research? Choose BMC and benefit from}

- fast, convenient online submission

- thorough peer review by experienced researchers in your field

- rapid publication on acceptance

- support for research data, including large and complex data types

- gold Open Access which fosters wider collaboration and increased citations

- maximum visibility for your research: over $100 \mathrm{M}$ website views per year

At BMC, research is always in progress.

Learn more biomedcentral.com/submissions 